\title{
New Onset of Atrial Fibrillation in a Medical ICU: Prevalence and Risk Factors
}

\author{
S. Della Ayed, S. Ayed, R. Atig, N. Tilouche, H. Ben Sik Ali, R. Gharbi, M. Fekih Hassen, \\ S. Elatrous*
}

Service de Réanimation Médicale, EPS Taher Sfar Mahdia, Mahdia, Tunisie.

Email: *Souheil.elatrous@rns.tn

Received September $25^{\text {th }}, 2012$; revised October $20^{\text {th }}, 2012$; accepted November $16^{\text {th }}, 2012$

\begin{abstract}
Objectives: To evaluate the prevalence and the risk factors of new onset atrial fibrillation (AF) in a single medical ICU. Methods: A prospective observational study was conducted in a 10 bed single medical ICU over a period of 18 months. All patients with sinus rhythm admitted in the medical ICU were included. Those presenting with any arrhythmia on admission, having a PACEMAKER or having undergone a recent cardiothoracic surgery were excluded. Results: Of the 377 patients included on the study, atrial fibrillation occurred in 26 patients (7\%). Patients who developed AF were older, had higher severity scores on admission, and required significantly more fluids, catecholamine, and mechanical ventilation. They had a longer ICU and hospital LOS. ICU mortality was significantly higher in AF patients. Five independent risk factors of $\mathrm{AF}$ were identified by multivariate analysis: advanced age, the presence of COPD, sepsis, cardiogenic shock, and hypoxemia. Conclusion: AF occurs in approximately $7 \%$ of medical critically ill patients and is associated with age, a history of COPD, the presence of sepsis, cardiogenic shock and hypoxemia. AF occurs in more critically ill patients and is associated with increased morbidity and mortality.
\end{abstract}

Keywords: Atrial Fibrillation; Medical ICU; Prevalence; Risk Factors

\section{Introduction}

Atrial fibrillation (AF) is the most common arrhythmia observed in whole population with an incidence of $0.5 \%$, increasing to $1 \%$ above 75 years $[1,2]$. It has been well established that AF in ICU is increased after cardiothoracic surgery and is associated with a high morbidity and mortality $[3,4]$.

In previous studies conducted in surgical or medicosurgical ICU, it was established that factors associated with AF were: severity of illness, trauma, cardiac surgery and intense inflammatory response, need for mechanical ventilation, catecholamine and fluids, and having a prolonged ICU stay $[3,5,6]$. When a multivariate analysis is performed, the most common risk factors associated with the development of AF are: elevated age, thoracic trauma, sepsis and severity of illness $[7,8]$.

In Tunisia, the real prevalence and the risk factors of new onset AF in a medical ICU are in our knowledge still undefined.

This prospective study was conducted to evaluate the incidence and the risk factors of new onset AF in a single medical ICU.

"Corresponding author.

\section{Materials and Methods}

This prospective observational study was conducted in a 10 bed medical ICU of a 500 bed Tunisian tertiary teaching hospital over a period of 18 months (from the $1^{\text {st }}$ of July 2009 to the $30^{\text {th }}$ of December 2010).

No informed consent was needed conforming to the decision of the local ethic committee.

Study design: All patients admitted to ICU with sinus rhythm were included. Those presenting with any arrhythmia on admission, having a Pacemaker or having undergone a recent cardiothoracic surgery were excluded.

All patients were continuously monitored (Nihon Coden monitor, Space Labs monitor).

$\mathrm{AF}$ was suspected if the ventricular rate was higher than 110 beats/min or lower than 110 beats/min and associated with an irregular R-R interval and confirmed by a 12-lead electrocardiogram revealing irregular, chaotic atrial activity with no apparent $P$ waves and with irregular ventricular activity [9].

The following variables were recorded for all patients: age, sex, comorbidity factors such as cardiovascular (hypertension, history of coronary artery disease, myocardial infarction, heart failure, cardiomyopathy), chronic 
pulmonary disease (COPD, obstructive sleep apnea) and diabetes mellitus. Previous regular medications were also recorded: $\beta$-blocking agents, calcium channel inhibitors, angiotensin converting enzyme inhibitors, diuretics, nitrates, any antiarrhythmic drugs, and inhalative $\beta$-adrenoreceptor agonist. The cause of admission in ICU was recorded.

The APACHE II [10] and Simplified Acute Physiology Score II (SAPS II) [11] were calculated 24 hours after admission. Workload was evaluated by OMEGA scoring [12].

Medical ICU and hospital length of stay (LOS) and mortality were recorded.

The following variables were recorded daily during the first 7 days of hospitalization in the ICU or until the onset of AF: fluid therapy if needed, mechanical ventilation, need and type of catecholamine(s), number of episodes of hypoxia, and the presence or absence of SIRS, sepsis, and acute renal failure. The presence of central venous catheter before the onset of $\mathrm{AF}$ and for patients who did not develop AF was recorded. The biological parameters such as serum levels of potassium, magnesium, creatinine, hematocrite and parotids were recorded during the first 7 days of hospitalization or until the AF occurred.

Systemic Inflammatory response syndrome (SIRS) was defined as the presence of at least two of the following criteria [13]: temperature above $38.0^{\circ} \mathrm{C}$ or below $36.5^{\circ} \mathrm{C}$, respiratory rate higher than 20 breaths/min or arterial $\mathrm{CO}_{2}$ tension lower than $32 \mathrm{mmHg}$ or need for mechanical ventilation, heart rate more than 90 beats $/ \mathrm{min}$, white blood cell count greater than $12 \times 10^{9} / 1$ or lower than $4 \times 10^{9} / 1$, blood Glucose more than $7.7 \mathrm{mmol} / \mathrm{l}$, capillary coloration time $>2$ seconds, lactates more than 2 $\mathrm{mmol} / \mathrm{l}$, and impaired neurologic functions. Sepsis was defined as SIRS associated with evidence of infection and septic shock as sepsis induced hypotension persisting despite adequate fluid resuscitation [14].

Hypoxemia was defined by pulse oximetry $\left(\mathrm{SpO}_{2}\right)$ lower than $90 \%$ for more than $10 \mathrm{~min}$.

Acute renal failure was defined according to the AKIN classification [15] either by a rise on serum creatinine above $50 \%$ and/or oliguria below $0.5 \mathrm{ml} / \mathrm{kg} /$ day for more than 6 hours and/or need for dialysis.

Statistical analysis:

Statistical analysis was performed by SPSS 17 software package.

For continuous variables, the mean $\pm \mathrm{SD}$ was reported, and for categorical variables the number of patients in each category and the corresponding percentage were given.

The characteristics of patients who developed AF and those who did not were compared using Student's t test for continuous variables, and the $\chi^{2}$ or Fisher's exact test for categorical variables.
To identify risk factors independently associated with the occurrence of $\mathrm{AF}$, variables found to be different with $\mathrm{p}<0.2$ between the two groups were entered into a forward stepwise logistic-regression model. All patients were entered in this model (no missing data).

\section{Results}

During the study period, a total of 377 patients were admitted to the medical ICU. The mean age was $55 \pm 20$ years and $55 \%$ were male.

The severity assessed by APACHEII and SAPSII scores was respectively $15 \pm 9$ and $31 \pm 8$. The major comorbidity observed was cardiovascular. Patients' medication history before admission includes beta-blockers in $4 \%$ of cases, calcium-channel-blockers in $15 \%$ of cases and inhibitors of angiotensin converting enzyme in $4 \%$ of cases. No patient was treated with digoxin.

Fifty per cent of patients were admitted for acute respiratory failure, $18 \%$ for shock and $12 \%$ for sepsis.

The mean ICU and hospital length of stay were $7 \pm 10$ days and $9 \pm 10$ days respectively. The overall mortality was $22.8 \%$.

The prevalence of new onset AF was 7\%. AF occurred mainly within the first three days after admission and lasted mainly for 24 hours. Patients with AF had higher SAPS II and APACHE II score (43 \pm 18 and $19 \pm 7$ respectively versus $30.2 \pm 17$ and $15.1 \pm 9$ respectively, $\mathrm{p}<$ $10^{-3}$ and $\mathrm{p}<0.021$ respectively), required significantly more fluid loading, catecholamine administration and mechanical ventilation. They experienced significantly more sepsis, hypoxemia and acute renal failure. Central venous catheters were inserted more frequently in $\mathrm{AF}$ patients (Table 1).

At the onset of AF, the biological parameters did not differ significantly between the two groups.

Workload evaluated by OMEGA scoring was significantly greater. Patients with AF had a significant longer ICU and hospital LOS. ICU mortality was higher among patients with new onset AF when compared with non AF patients (Table 2).

The treatment of AF consisted of electrical cardioversion and Amiodarone in 42\% (11/26) of patients with AF. Amiodarone alone was used in $23 \%$ (6/26) of patients. Digoxin and Diltiazem were administered along with Amiodarone in two and one patient respectively.

For four patients, AF resolved spontaneously and for four other patients, additional treatment with potassium and magnesium was administered.

$\mathrm{AF}$ resolved only in $56 \%$ of patients, in a mean delay of 14 hours.

The multivariate logistic regression analysis examining the independent risk factors of developing $\mathrm{AF}$ is illustrated in Table 3. The advanced age, the presence of 
Table 1. Demographic and clinical characteristics in patients with and without atrial fibrillation (univariate analysis).

\begin{tabular}{|c|c|c|c|}
\hline & $\begin{array}{c}\text { Atrial } \\
\text { fibrillation } \\
\mathbf{n}=\mathbf{2 6}\end{array}$ & $\begin{array}{c}\text { No atrial } \\
\text { fibrillation } \\
\mathbf{n}=351\end{array}$ & $\mathbf{p}$ \\
\hline Age (years) ${ }^{\mathrm{a}}$ & $65 \pm 16$ & $54 \pm 21$ & 0.012 \\
\hline Male/female, $\mathrm{n}$ & $17 / 9$ & $191 / 160$ & 0.312 \\
\hline \multicolumn{4}{|l|}{ Medical history, n (\%) } \\
\hline Hypertension & $13(50)$ & $124(35)$ & 0.143 \\
\hline Coronary heart disease & $3(11)$ & $21(6)$ & 0.224 \\
\hline COPD & $8(30)$ & $63(18)$ & 0.119 \\
\hline Obstructive sleep apnea & $1(4)$ & $9(34)$ & 0.515 \\
\hline Diabetes & $9(34)$ & $103(29)$ & 0.657 \\
\hline Calcium channel blockers & $3(11)$ & $51(14)$ & 0.472 \\
\hline \multicolumn{4}{|l|}{ Variables on admission } \\
\hline SAPSII $^{\mathrm{a}}$ & $43 \pm 18$ & $30 \pm 17$ & $<10^{-3}$ \\
\hline APACHEII $^{\mathrm{a}}$ & $19 \pm 7$ & $15 \pm 9$ & 0.021 \\
\hline Sepsis on admission, $\mathrm{n}(\%)$ & $12(46)$ & $43(12)$ & $<10^{-3}$ \\
\hline Cardiogenic shock, n (\%) & $7(27)$ & $33(9)$ & 0.013 \\
\hline Hypoxemia, n (\%) & $12(46)$ & $26(7)$ & $<10^{-3}$ \\
\hline Acute renal failure, n (\%) & $8(30)$ & $24(7)$ & 0.001 \\
\hline \multicolumn{4}{|l|}{ Medication, n (\%) } \\
\hline Fluid loading & $14(53)$ & $61(17)$ & $<10^{-3}$ \\
\hline Catecholamines & $18(69)$ & $71(20)$ & $<10^{-3}$ \\
\hline Norepinephrine & $13(50)$ & $43(12)$ & $<10^{-3}$ \\
\hline Dobutamine & $6(23)$ & $23(6)$ & 0.009 \\
\hline Central venous catheter & $16(61)$ & $61(17)$ & $<10^{-3}$ \\
\hline
\end{tabular}

COPD: chronic obstructive pulmonary disease; SAPSII: simplified acute physiology score II; APACHEII: acute physiological and chronic health evaluation score; ${ }^{\mathrm{a}}$ mean $\pm \mathrm{SD}$.

Table 2. Outcomes of patients with and without atrial fibrillation.

\begin{tabular}{lccc}
\hline & $\begin{array}{c}\text { Atrial } \\
\text { fibrillation } \\
\mathbf{n}=\mathbf{2 6}\end{array}$ & $\begin{array}{c}\text { No atrial } \\
\text { fibrillation } \\
\mathbf{n}=\mathbf{3 5 1}\end{array}$ & $\mathbf{p}$ \\
\hline OMEGA score, mean \pm SD & $227 \pm 209$ & $77 \pm 131$ & $<10^{-3}$ \\
ICU LOS, days & $13 \pm 12$ & $7 \pm 10$ & 0.007 \\
Hospital LOS, days & $15 \pm 11$ & $10 \pm 10$ & 0.033 \\
Mortality, n (\%) & $15(57)$ & $71(20)$ & $<10^{-3}$ \\
\hline
\end{tabular}

OMEGA: intensive care workload; ICU: intensive care unit, LOS: length of stay.
Table 3. Logistic regression analysis for risk factors of atrial fibrillation.

\begin{tabular}{ccc}
\hline & OR 95\% CI & p \\
\hline Age & $1.03(1.001-1.065)$ & 0.041 \\
COPD & $3.75(1.212-11.612)$ & 0.022 \\
Sepsis on admission & $6.94(1.797-26.846)$ & $<0.005$ \\
Cardiogenic shock & $5.55(1.417-21.776)$ & 0.014 \\
Hypoxemia & $6.38(2.071-19.677)$ & 0.001 \\
\hline
\end{tabular}

COPD: chronic obstructive pulmonary disease; OR: odds ratio; CI: confidence interval.

COPD, sepsis, cardiogenic shock and hypoxia were significantly associated with the occurrence of AF.

\section{Discussion}

To our knowledge, this is the first study conducted in a single medical ICU analysing the prevalence and the risk factors of new onset atrial fibrillation in medical patients.

Overall prevalence of new onset AF in our study was $7 \%$.

Patients experiencing AF were more critically ill and septic, requiring more supportive therapy with mechaniccal ventilation, catecholamine and fluid loading and developing more hypoxia and acute renal failure. Length of stay in ICU and in hospital was higher in AF patients and mortality was significantly elevated. The independent risk factors of developing atrial fibrillation are advanced age, sepsis, COPD, cardiogenic shock and hypoxia.

The incidence of atrial fibrillation found in our study seems consistent with previous studies performed in non cardiac ICU's or in medico-surgical ICU's (1.8\% to $10 \%)$ [3,5,6,8,16-20], although, many of these studies did not focus only on atrial fibrillation and have evaluated a broad variety of arrhythmias. In the study by Seguin et al. [17], AF occurred in $5.5 \%$ of all exclusively trauma patients. Annane and al [8] in a multicenter study conducted in a medico-surgical ICU with $76 \%$ of patients being medical found $6.5 \%$ of new onset AF. Knotzer and al [6] performed a study in a surgical ICU with two third of patients having undergone a cardiothoracic surgery and reported $9 \%$ of $\mathrm{AF}$.

Age is a well-recognized risk factor of $\mathrm{AF}$ in the general population as well as in ICU. In our study, age was found to be an independent risk factor of AF. Similarly, in the study by Knotzer [6] and Reinelt [1], advanced age was an independent risk factor of $\mathrm{AF}$ and the mean age of patients with $\mathrm{AF}$ was $68 \pm 12$ and $65 \pm 12$ years respectively. Amar et al. [21] showed that some changes in the atrial configuration are observed with age including atrial dilation and fibrosis. Atrophy of the atrial muscle can be aggravated with age leading to loss of atrial con- 
traction and conduction [22].

COPD was a second independent risk factor of AF in our study population. This may be explained by the structural changes induced in the heart including a change on the right atrium and ventricular functions [23].

SIRS and Sepsis are now well known to be associated with AF. In our study, sepsis was an independent risk factor of developing AF. Several studies showed the same conclusion: Knotzer et al. [6] found SIRS in $85 \%$ of patients with tachyarrhythmia ( $60 \%$ of AF). Seguin et al. [3] found SIRS in 50\% of patients with AF. There is actually increasing evidence that the systemic inflammatory response is a predominant trigger of $\mathrm{AF}$ in critically ill patients. Some studies have demonstrated an association of elevated CRP levels with the development and maintenance of AF [14,24,25]. Chung and colleagues [26] found two-fold higher CRP levels in patients with AF than in control subjects. Furthermore, patients with persistent AF had higher CRP levels than those with paroxysmal AF, suggesting that inflammation plays an important role in the maintenance of $\mathrm{AF}$ [26].

We found that patients developing new onset AF experienced more cardiogenic shock. This can be in part explained by SIRS that occurs after myocardial infarction, increasing the inflammatory response and leading to the development and the maintenance of AF as described above [24]. On the other hand, acute changes of the cardiac functions may induce persistent AF.

In addition to these factors, hypoxemia was an important risk factor of AF in our study. This factor was found by Knotzer et al. [6], but in the Seguin study, no significant difference was found [3]. Hypoxemia is susceptible to produce a multitude of myocardial electro physicologic effects and a broad variety of arrhythmias including $\mathrm{AF}$ [27].

Hypotention and consequently the use of catecholamine were identified as risk factor only in univariate analysis in our study. In ICU patients the administration of exogenous catecholamines elicits both $\alpha$ - and $\beta$ adrenergic receptors that favor the risk of arrhythmia [28].

Sex and severity of illness were the other independent risk factors found in the previous studies. In our study, these factors differed significantly between patients with $\mathrm{AF}$ and controls, but they were not independently associated with $\mathrm{AF}$.

Amiodarone the most used antiarrhythmic drug therapy used in our study, is an effective and safe drug for converting AF to sinus rhythm. Conversion of AF should not be attempted $48 \mathrm{~h}$ after onset without anticoagulation or transesophageal echocardiography to rule out intracardiac thrombus formation. In order to avoid thromboembolism after cardioversion, an effective anticoagulation is mandatory.
Finally, as others $[3,17]$, we found that new onset AF result in longer ICU and hospital stay and increased mortality [18].

In conclusion, our study showed that AF occurs in approximately $7 \%$ of medical critically ill patients and is associated with age, a history of COPD, the presence of sepsis, cardiogenic shock and hypoxemia. AF occurs in more critically ill patients and is associated with increased morbidity and mortality in ICU.

\section{REFERENCES}

[1] P. Reinelt, G. D. Karth, A. Geppert and G. Heinz, "Incidence and Type of Cardiac Arrhythmias in Critically Ill Patients: A Multicenter Experience in a Medical-Cardiological ICU," Intensive Care Medicine, Vol. 27, No. 9, 2001, pp. 1466-1473. doi:10.1007/s001340101043

[2] C. D. Furberg, B. M. Psaty, T. A. Manolio, J. M. Gardin, V. A. Smith and P. M. Rautaharju, "Prevalence of Atrial Fibrillation in Elderly Subjects (The Cardiovascular Health Study)," American Journal of Cardiology, Vol. 74, No. 3, 1994, pp. 236-241. doi:10.1016/0002-9149(94)90363-8

[3] P. Seguin, T. Signouret, B. Laviolle, B. Branger and Y. Mallédant, "Incidence and Risk Factors of Atrial Fibrillation in a Surgical Intensive Care Unit," Critical Care Medicine, Vol. 32, No. 3, 2004, pp. 722-726. doi:10.1097/01.CCM.0000114579.56430.E0

[4] W. B. Kannel, R. D. Abbott, D. D. Savage and P. M. McNamara, "Coronary Heart Disease and Atrial Fibrillation: The Framingham Study," American Heart Journal, Vol. 106, No. 2, 1983, pp. 389-396. doi:10.1016/0002-8703(83)90208-9

[5] H. Artucio and M. Peireira, "Cardiac Arrhythmias in Critically Ill Patients: Epidemiologic Study," Critical Care Medicine, Vol. 18, No. 12, 1990, pp. 1383-1388. doi:10.1097/00003246-199012000-00015

[6] H. Knotzer, A. Mayr, H. Ulmer, W. Lederer, W. Schobersberger, N. Mutz and W. Hasibeder, "Tachyarrhythmias in a Surgical Intensive Care Unit: Case-Controlled Epidemiologic Study," Intensive Care Medicine, Vol. 26, No. 7, 2000, pp. 908-914. doi:10.1007/s001340051280

[7] W. H. Maisel, J. D. Rawn and W. G. Stevenson, "Atrial Fibrillation after Cardiac Surgery," Annals of Internal Medicine, Vol. 135, 2001, pp. 1061-1073.

[8] D. Annane, V. Sebille, D. Duboc, J. Y. LeHeuzey, N. Sadoul, E. Bouvier, et al., "Incidence and Prognosis of Sustained Arrhythmias in Critically Ill Patients," American Journal of Respiratory and Critical Care Medicine, Vol. 178, No. 1, 2008, pp. 20-25. doi:10.1164/rccm.200701-0310C

[9] S. M. Hollenberg and R. P. Dellinger, "Non Cardiac Surgery: Post Operative Arrhythmias," Critical Care Medicine, Vol. 28, No. 10, 2000, pp. 145-150. doi:10.1097/00003246-200010001-00006

[10] W. A. Knaus, E. A. Draper, D. P. Wagner and J. E. Zimmerman, "APACHEII. A Severity Score of Disease Classification System," Critical Care Medicine, Vol. 13, 
No. 10,1985 , pp. $818-829$. doi:10.1097/00003246-198510000-00009

[11] J. R. Le Gall, S. Lemeshow and F. Saulnier, "A New Simplified Acute Physiology Score (SAPSII) Based on a European/North American Multicenter Study," Journal of the American Medical Association, Vol. 270, 1993, pp. 2957-2963. doi:10.1001/jama.270.24.2957

[12] Commission d'Evaluation de la Société de Réanimation en Langue Française. Utilisation de l'Indice de Gravité Simplifié et du Système Oméga. Mise à Jour 1986," Réanimation Soins Intensifs Med Urgences, Vol. 2, 1986, pp. 219-221.

[13] M. M. Levy, M. P. Fink, J. C. Marshall, E. Abraham, D. Angus, D. Cook, J. Cohen, S. M. Opal, J. L. Vincent and G. Ramsay, "2001 SCCM/ESICM/ACCP/ATS/SIS International Sepsis Definitions Conference," Critical Care Medicine, Vol. 31, No. 4, 2003, pp. 1250-1256. doi:10.1097/01.CCM.0000050454.01978.3B

[14] M. M. Levy, J. M. Carlet, J. Bion, M. M. Parker, R. Jaeschke, et al., "Surviving Sepsis Campaign: International Guidelines for Management of Severe Sepsis and Septic Shock: 2008," Intensive Care Medicine, Vol. 34, No. 1, 2008, pp. 17-60. doi:10.1007/s00134-007-0934-2

[15] R. L. Mehta, J. A. Kellum, S. V. Shah, B. A. Molitoris, C. Ronco, et al., "Acute Kidney Injury Network: Report of an Initiative to Improve Outcomes in Acute Kidney Injury," Critical Care, Vol. 11, 2007, p. R31. doi:10.1186/cc5713

[16] R. Meierhenrich, E. Steinhilber, C. Eggermann, M. Weiss, et al., "Incidence and Prognostic Impact of New-Onset Atrial Fibrillation in Patients with Septic Shock: A Prospective Observational Study," Critical Care, Vol. 14, 2010, p. R108. doi:10.1186/cc9057

[17] P. Seguin, B. Laviolle, A. Maurice, C. Leclercq and Y. Malledant, "Atrial Fibrillation in Trauma Patients Requiring Intensive Care," Intensive Care Medicine, Vol. 32, No. 3, 2006, pp. 398-404. doi:10.1007/s00134-005-0032-2

[18] D. Brathwaite and C. Weissman, "The New Onset of Atrial Arrhythmias Following Major Noncardiothoracic Surgery Is Associated with Increased Mortality," Chest, Vol. 114, No. 2, 1998, pp. 462-468. doi:10.1378/chest.114.2.462

[19] L. Goldman, "Supraventricular Tachyarrhythmias in Hospitalized Adults after Surgery. Clinical Correlates in Patients over 40 Years of Age after Major Noncardiac Surgery," Chest, Vol. 73, No. 4, 1978, pp. 450-454. doi: $10.1378 /$ chest.73.4.450

[20] J. S. Bender, "Supraventricular Tachyarrhythmias in the Surgical Intensive Care Unit: An Under-Recognized Event," American Surgeon, Vol. 62, No. 1, 1996, pp. 73 75.

[21] D. Amar, H. Zhang, D. H. Y. Leung, N. Poistacher and A. H. Kadish, "Older Age Is the Strongest Predictor of Postoperative Atrial Fibrillation," Anesthesiology, Vol. 96, No. 2, 2002, pp. 352-356. doi:10.1097/00000542-200202000-00021

[22] B. M. Psaty, T. A. Manolio, L. H. Kuller, R. A. Kronmal, M. Cushman, L. P. Fried, et al., "Incidence and Risk Factors for Atrial Fibrillation in Older Adults," Circulation, Vol. 96, No. 2, 1997, pp. 2455-2461. doi:10.1161/01.CIR.96.7.2455

[23] T. Liu, G. P. Li and L. J. Li, "Atrial Dilatation and Atrial Fibrillation: A Vicious Circle?" Medical Hypotheses, Vol. 65, No. 2, 2005, pp. 410-411. doi:10.1016/i.mehy.2005.03.004

[24] T. T. Issac, H. Dokainish and N. M. Lakkis, "Role of Inflammation in Initiation and Perpetuation of Atrial Fibrillation: A Systematic Review of the Published Data," Journal of the American College of Cardiology, Vol. 50, No. 21, 2007, pp. 2021-2028. doi:10.1016/j.jacc.2007.06.054

[25] R. J. Aviles, D. O. Martin, C. Apperson-Hansen, P. L. Houghtaling, P. Rautaharju, R. A. Kronmal, R. P. Tracy, D. R. Van Wagoner, B. M. Psaty, M. S. Lauer and M. K. Chung, "Inflammation as a Risk Factor for Atrial Fibrillation," Circulation, Vol. 108, 2003, pp. 3006-3010. doi:10.1161/01.CIR.0000103131.70301.4F

[26] M. K. Chung, D. O. Martin, D. Sprecher, O. Wazni, A. Kanderian, C. A. Carnes, J. A. Bauer, P. J. Tchou, M. J. Niebauer, A. Natale and D. R. Van Wagoner, "C-Reactive Protein Elevation in Patients with Atrial Arrhythmias: Inflammatory Mechanisms and Persistence of Atrial Fibrillation," Circulation, Vol. 104, 2001, pp. 2886-2891. doi:10.1161/hc4901.101760

[27] K. Ramaswamy and M. H. Hamdan, "Ischemia, Metabolic Disturbances and Arrhythmogenesis: Mechanisms and Management," Critical Care Medicine, Vol. 28, No. 10, 2000, pp. 151-157. doi:10.1097/00003246-200010001-00007

[28] S. M. Hollenberg and R. P. Dellinger, "Noncardiac Surgery: Postoperative Arrhythmias," Critical Care Medicine, Vol. 28, No. 10, 2000, pp. 145-150. doi:10.1097/00003246-200010001-00006 